\title{
Analysis on Regional Technology Innovation Efficiency Evaluation and Influence Factors in China
}

\author{
Xin $\mathrm{Xie}^{1}$ \& Fangfang Liu $^{2}$ \\ ${ }^{1}$ School of Public Affairs, University of Science and Technology of China, China \\ ${ }^{2}$ School of Management, University of Science and Technology of China, China \\ Correspondence: Fangfang Liu, School of Management, University of Science and Technology of China, Hefei, \\ Anhui, 230026, China. E-mail: 120563762@qq.com
}

Received: October 20, 2014

doi:10.5539/ijbm.v10n3p169
Accepted: January 16, 2015

Online Published: February 27, 2015

URL: http://dx.doi.org/10.5539/ijbm.v10n3p169

\begin{abstract}
Based on the starting point of enterprise as the mainstay of technological innovation, the stochastic frontier analysis (SFA) method was used to calculate the innovation efficiency and non efficiency factors. The results show that cooperation between major actors and the absorption ability has a positive influence on innovation efficiency, but the patent stock that enterprise owns and the import of technology has a negative influence on innovation efficiency. The regional innovation efficiency of China presents rising trend on the whole, and the innovation efficiency value fluctuates between $0.3 \sim 0.5$, and there is still larger room for improvement in the future.
\end{abstract}

Keywords: regional technology innovation, main center, efficiency, SFA

\section{Introduction}

With the deepening of global integration, the development trend of the world economy presents a significant regional characteristics in modern world. A new division of the world economy is no longer to countries, but turned to the area. Regional science and technology innovation ability gradually become one regional economic development power to drive the country took off, finally obtain the decisive factors in the international competition advantage. China is in a special period of economic transition, there is a huge difference between different regions both in natural endowment conditions and level of economic development, It is an extremely difficult task how to implement the regional economic rapid, sustained and healthy development in this period. As endogenous dynamic of economic growth, regional scientific and technological progress as the core connotation of the innovation become the key point.

Since 2006, research and development (R\&D) funds in China has achieved more than 20\% growth each year, from 300 billion yuan in 2006, rising to 2011 reached 127 billion dollars(the average exchange rate at 6.77 in conservative calculations), has become to the third in world, funds accounted for the proportion of gross domestic product (GDP) has increased from $1.42 \%$ to $1.83 \%$. Mismatching is, however, the current scale of large and medium-sized industrial enterprises in our country, the research and development funding and sales income, accounting for less than $2 \%$. This data compared with traditional developed countries generally has reached 3\% of the gap is still large. At present, many of Industry-University projects in our country have development potential, and the core competitiveness, which is still dominated by colleges and universities or research institutes, led to the plight of free in core decisions. In many important research topics of the development of enterprise technology innovation strategy, as a more pressing and motivation demands of industry sector, but can't get to participate in important decision-making rights (Feng, 2006).

Therefore, in order to truly achieve and strengthen the main body status of enterprises in technological innovation process, we should be first to give companies more channel of opinions in the decision-making process. Only when the innovation activity can, in accordance with the rules of market operation, the innovation of the enterprise itself and profit demands to get attention and recognition, and put the independent innovation as the basic way to enterprise survival and development, thus willing to innovation, improving inputs. While universities and research institutions should be gradually turned to give corresponding technical support for enterprise innovation and talent service, continue to promote technology and knowledge transfer to enterprise, promote the efficiency of the whole innovation in science and technology in the collaborative interaction of 
ascension.

\section{Research Method the Construction of SFA Model}

At present, innovation pattern in our country is gradually turned to landscape dominated by large and medium-sized industrial enterprises, enterprise R\&D activities proportion also increased year by year, by 2011 , the national science and technology activities of R\&D expenses within budget and full-time personnel of enterprises in the equivalent proportion are $75.7 \%$ and $75.2 \%$ respectively, it is not hard to see that the section on the $R \& D$ resources configuration, enterprises in terms of absolute size, has occupied the dominant position of regional innovation activities, but how the enterprise R\&D input--output efficiency levels, is much more worthy of attention and rich practical problems(Wang et al., 2012). This paper uses the stochastic frontier analysis (SFA) methods, by determining the enterprises as the main body in the measure of science and technology innovation output dependent variable, and select the corresponding technological innovation capital and human factors of two classic variables, and the innovation of several representative technical efficiency factors influencing variables, and do further study to our country current regional innovation level and efficiency.

"Stochastic frontier analysis" is a kind of parameterized tool that according to the observed value of input and output form all possible combinations of production possibility frontier, through comparison of the distance between the sample and the efficient frontier and to determine the relative efficiency (Aigner, 1977). And as a representative of the nonparametric method of data envelopment analysis (DEA), compared with SFA, the data envelopment analysis (DEA) focuses on measuring the overall efficiency, but can't measure the random error of the impact of different evaluation indexes, as well as for measuring the technical efficiency of the individual differences of the endogenous factors. Stochastic frontier analysis (SFA) is able to overcome the above problems, separating the random error and the efficiency value, and use the measurement method to estimate the frontier function. At the same time, the SFA method can not only measure the individual's technical efficiency, also can quantitatively analyze the influence of related factors on the efficiency of individual differences. Which matches with this paper systematically explores the efficiency of regional technological innovation process and the factors affecting efficiency, as well as the random error term with the efficiency of the research goals about the degree of impact on the efficiency, so as to realize the target, measuring and evaluating the efficiency level of the regional scientific and technological innovation in China (Feng H., 2004).

\section{The Construction of SFA Model}

This article uses panel data of stochastic frontier model that is proposed by Lovell and Kumbhakar, its general form is:

$$
Y_{i t}=f\left(x_{i t}, t\right) \cdot \exp \left(v_{i t}-u_{i t}\right)
$$

Among them, $Y_{i t}$ represents decision making units $i(i=1, \ldots, N)$ within a certain time $t(1, \ldots, T)$ of output level, $f(\cdot)$ represents the production possibility set boundaries determine the production frontier, ${ }^{x_{i t}}$ represents a set of unit input variables. And the parameters $v_{i t}-u_{i t}$ is belong to the compound composition, $v_{i t}$ is only parts of following $N\left(0, \sigma_{v 2}\right)$ distribution, representing the random disturbance influence level; While $u_{i t}$ part represents the technical efficiency of the item, ${ }^{\left(u, \sigma_{u}^{2}\right)}$ follows, on behalf of the influence of a single element. And $T E_{i t}=\exp (-u i t)$ represents the expectations of the ratio between the actual output and the efficiency of production frontier, so-called technical efficiency, if $T E_{i t}=1$, decision making units is efficient, or decision making units did not fall on the production frontier, which is inefficient.

Both sides of (1) take the logarithm respectively, then the logarithmic form of stochastic frontier model can be obtained, like the type (2):

$$
\operatorname{Ln} Y_{i t}=\beta x_{i t}+v_{i t}-u_{i t}
$$

According to the study design by Battese and Coelli (1995), this paper sets up the parameter variance $\gamma=\sigma_{u}^{2} /\left(\sigma_{v}^{2}+\sigma_{u}^{2}\right)$ to measure the disturbance in the proportion of inefficient item, also the value $\gamma$ is greater than zero and less than 1, if $\gamma=0$ is the fact, then it shows that the actual output and the ideal output of distance caused by systematically irresistible factors, then we don't have to use the stochastic frontier analysis method deal with sample data, but using OLS method to measure.

At the same time, in order to effectively explained the efficiency of the existing differences between the decision-making units, we need further research and add technologically invalid function:

$$
u_{i t}=\delta_{0}+z_{i t} \delta+w_{i t}
$$


Among them, $\delta_{0}$ represents the constant parameters, ${ }_{i t}$ represents the exogenous variables of technical efficiency, ${ }^{w_{i t}}$ represents the error parameter, follow the $N\left(0, \sigma^{2}\right)$ distribution.

\section{Variable Selection and Data Sources}

a) Input indicators

Follow the setting by cobb-douglas function, innovation investment in capital and manpower of two parts of the main variables. Because we view enterprise as one of three participations in the body of industry-university-research cooperation of the main investigation object, and scientific and technological innovation process in test and development phase in this section, whether R\&D fund or human scale is majority. So we selected test and development stages of R\&D spending (ten thousand Yuan) and the R\&D personnel full-time equivalent (people/year) two indicators, respectively as the main representation for enterprise innovation of regional scientific and technological innovation activities in the capital and human two indicators (Gu H., 2010).

\section{b) Output indicators}

For measuring the innovation output indicator on the question of how to select, most scholars used to adopt patent authorization number or new product sales to consider these two indicators. But the two measures have different emphasis of the characterization, patent authorization number usually reflects the regional technology innovation process shelter-forest and research institutions in the middle of the output, it does not have a direct economic output value, and also its patent quality between the good and bad are intermingled reflects comprehensively the research and development of science and technology and economic value, so it is not suitable for measuring index of the regional innovation output as the final measure. And new product output value as the material objects of the innovation, the size of the producers of confidence reflects the innovation achievements and consumer acceptance of the market, more centered on enterprise technology innovation level. Therefore, this research adopts the new product output of large and medium-sized industrial enterprises in our country (ten thousand yuan) as a characterization of regional scientific and technological innovation output indicator.

\section{Factors Affecting the Efficiency}

With enterprise as the main body of regional innovation embodies the regional innovation system in enterprises, universities and research institutions such as the coupling relationship between multiple action subject level, the knowledge transfer and cooperation model and so on, various factors will impact on production efficiency. To highlight the regional innovation in organic coupling between different subjects, collaborative symbiotic relationship characteristics, we select the following factors affecting the efficiency study in this study (Bai, J., 2010).

a. the patent stock. The stock of knowledge level of high or low for the next step of innovation behavior has a crucial influence in large and medium-sized industrial enterprise, the research has a patent for invention for (a) to characterize the indicators in large and medium-sized industrial enterprises .

b. cooperation level. The enterprises can help the colleges and universities and research institutions in cooperative innovation,which is indispensable for enhancing regional innovation efficiency. Research in the universities and research institutions of scientific research activities to raise money from enterprises fund (ten thousand yuan) to characterize the indicators.

c. technology purchase. The research adds the purchasing domestic large and medium-sized enterprises of expense (ten thousand yuan) and foreign technology import expense (ten thousand yuan) to represent the enterprise technology purchase index variables.

d. transformation ability. In large and medium-sized enterprises in the study of absorption expense (ten thousand yuan) and technical renovation expense (ten thousand yuan) are added to complete enterprise transformation ability index variables.

With reference to Battese and Coelli using both capital and labor inputs of cobb - Douglas production function research model set, the stochastic frontier production function can be expressed:

$$
\operatorname{Ln} Y_{i}=\beta_{0}+\beta_{1} L n K_{i t}+\beta_{2} L n L_{i t}+v_{i t}-u_{i t}
$$

Among them, $Y_{i}$ represnts the region $\mathrm{i}$ in $\mathrm{t}$ years of new product output in large and medium-sized enterprises , $K_{i t}$ and $L_{i t}$ respectively in the region i in t years of trials and development section R\&D expense (ten thousand yuan) and the R\&D personnel full-time equivalent (per year). Patent ${ }_{i t}$ represents the region i in t years of large and medium-sized industrial enterprises with invention patent number (item), ${ }^{\text {Cooper }}{ }_{\text {it }}$ represents the region $\mathrm{i}$ in $\mathrm{t}$ 
years of universities and research institutes of enterprises in the scientific research activities to raise the amount

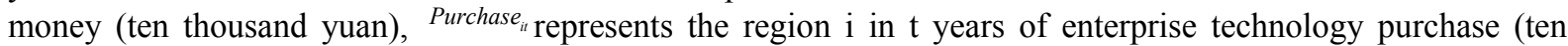
thousand yuan), Assimi $i_{i t}$ represents the region $\mathrm{i}$ in $\mathrm{t}$ years of enterprise transformation ability (ten thousand yuan).

\section{Source of Data and Instructions}

The data we used in this research from 2006 to 2012 periods of science and technology of China statistical yearbook. Considering the index data interval of time is too long, during the change of price index is larger, in order to ensure the validity of data comparison, this paper studies use the year of 2006 for adjusting base, build $\mathrm{R} \& \mathrm{D}$ expenditures on price deflator, and R\&D personnel full-time equivalent and all of the money to patent number data are the deflator.

On regional innovation about the hysteresis effect between R\&D input and output, from many scholars' study in China can find that we use stochastic frontier analysis method for panel data analysis need not worry about time lag for a credible level will affect the results of the study, so we don't take delay processing. Given in table 1 stochastic frontier analysis model of input variable and output variable will be used as well as the descriptive statistics of the technical efficiency factors:

Table 1. Descriptive statistics result of stochastic frontier analysis model of the variable

\begin{tabular}{lllll}
\hline index & $\begin{array}{l}\text { sample } \\
\text { number }\end{array}$ & mean value & $\begin{array}{l}\text { standard } \\
\text { deviation }\end{array}$ & $\begin{array}{l}\text { Maximum } \\
\text { value }\end{array}$ \\
\hline Y(hundred million dollars) & 210 & 245.007 & 317.714 & 1923.206 \\
K(hundred million dollars) & 210 & 0.885 & 1.208 & 5.166 \\
L(Ten thousand people/year) & 210 & 127.766 & 176.077 & 985.221 \\
Patent (ten thousand item) & 210 & 0.272 & 0.635 & 6.645 \\
Cooper (hundred million dollars) & 210 & 1.498 & 1.793 & 10.218 \\
Purchase (hundred million dollars) & 210 & 2.456 & 2.792 & 12.385 \\
Assimi (hundred million dollars) & 210 & 245.007 & 317.714 & 0.000 \\
\hline
\end{tabular}

Notes. The average exchange rate at 7.23 in conservative calculations(from 2006 to 2012).

\section{The Empirical Analysis}

With 30 provinces in China from 2006 to 2012 (because of missing data in Tibet area, this paper not to be counted) panel data analysis in the construction of stochastic frontier model, the results are as follows:

(1) Not considering the calculation results of efficiency factors. Using Frontier 4.1 analysis tools for estimating frontier production function withnot considering influence factors, and then we get model 1 parameter estimate and its test results without considering factors affecting the efficiency, as shown in Table 2.

Table 2. The stochastic frontier analysis and calculation without considering efficiency factors affecting the results

\begin{tabular}{llll}
\hline variable & Model 1 & standard error & T value \\
\hline constant term & $9.271^{* * *}$ & 0.967 & 9.568 \\
LnK & $0.543^{* * *}$ & 0.039 & 14.014 \\
LnL & 0.044 & 0.073 & 0.609 \\
Sigma-Squared & $1.699^{* * *}$ & 0.521 & 3.263 \\
Gamma & $0.906^{* * *}$ & 0.521 & 3.263 \\
Likelihood function value & -150.660 & & \\
LR inspection & $109.173^{* * *}$ & \\
\hline Note. ${ }^{*}, * * * *$ Respectively under the significant level of $10 \%, 5 \%, 1 \%$, as listed in the table below. &
\end{tabular}

From the results of the model, it is not hard to find that $\gamma$ value is greater than 0.8 and under the significant level of less than $1 \%$ successfully passed the test, it also can reflect the use of stochastic frontier analysis (SFA) to measure the author used the data sample is reasonable and scientific. And $\beta 0$ and $\beta 1$ are also passed the inspection under the significant level of less than $1 \%$, and estimated value $\beta 1$ reaches 0.543 , and it shows that 
regional $R \& D$ expenditure for innovation of output is in a stage of increasing economies of scale influence in our country at present, the increase of expenditure can still bring more significantly new product output increasing with the economic effect. But the value of $\beta 2$ is negative, and its estimated value is significant level under $10 \%$, the confidence coefficient is not high, we are going to make further discussion below.

(2) considering the efficiency factors of calculation results. using Frontier 4.1 analysis tools, and join the influence of the interaction effect, then with considering factors under the frontier production function to estimate, We get the parameters estimated value and test results of model 2 to 5 with considering factors of affecting efficiency, as shown in table 3 :

Table 3. The stochastic frontier analysis and calculation results with considering factors of affecting efficiency

\begin{tabular}{|c|c|c|c|c|c|c|c|c|}
\hline Variable & Model 2 & T value & Model 3 & T value & Model 4 & T value & Model 5 & T value \\
\hline \multicolumn{9}{|c|}{ Frontier function estimation } \\
\hline constant term & $10.578 * * *$ & 12.417 & $3.631 * * *$ & 12.894 & $10.740^{* * *}$ & 13.885 & $10.085^{* * *}$ & 22.391 \\
\hline LnK & $0.312 * * *$ & 34.76 & $0.783^{* * *}$ & 14.747 & $0.247 * *$ & 1.991 & $0.364 * * *$ & 7.731 \\
\hline LnL & $0.259 * * *$ & 4.246 & $0.199 * * *$ & 3.355 & $0.307 * * *$ & 2.624 & $0.209 * * *$ & 3.925 \\
\hline \multicolumn{9}{|c|}{ Technical efficiency function estimation } \\
\hline constant term & $5.509 * * *$ & 7.627 & $8.549^{* * *}$ & 10.420 & $7.179 * * *$ & 5.890 & $8.182 * * *$ & 8.608 \\
\hline LnPatent & $-0.392 * * *$ & -7.567 & $0.991 * * *$ & 3.963 & $2.052 * * *$ & 3.733 & $2.625 * * *$ & 4.537 \\
\hline LnCooper & 0.171 & 0.394 & -0.270 & -0.885 & $-1.228 * * *$ & -2.969 & $-1.616^{* * *}$ & -3.428 \\
\hline LnPurchase & $-0.240 * * *$ & -5.929 & -0.162 & -0.603 & $0.814^{*}$ & 1.923 & $1.214 * *$ & 2.388 \\
\hline LnAssimi & 0.075 & 1.122 & $-1.844 * * *$ & -7.592 & $-1.301 * * *$ & -3.074 & $-1.875^{* * *}$ & -3.728 \\
\hline LnK $\times$ LnPatent & & & $-0.121 * * *$ & -6.191 & & & $-0.295 * * *$ & -3.234 \\
\hline LnK $\times$ LnCooper & & & 0.022 & 0.868 & & & 0.112 & 1.530 \\
\hline LnK $\times$ LnPurchase & & & -0.019 & -0.867 & & & -0.076 & -1.230 \\
\hline LnK $\times$ LnAssimi & & & $0.140 * * *$ & 7.750 & & & $0.137 * * *$ & 2.608 \\
\hline LnL $\times$ LnPatent & & & & & $-0.234 * * *$ & -4.544 & 0.067 & 0.627 \\
\hline LnL $\times$ LnCooper & & & & & $0.112 * * *$ & 2.742 & 0.007 & 0.092 \\
\hline LnL $\times$ LnPurchase & & & & & $-0.103 * *$ & -2.356 & -0.050 & -0.642 \\
\hline LnL $\times$ LnAssimi & & & & & $0.127 * * *$ & 3.067 & 0.013 & 0.192 \\
\hline Sigma-Squared & $0.342 * * *$ & 15.791 & $0.318 * * *$ & 10.144 & $0.331 * * *$ & 6.627 & $0.318 * * *$ & 7946 \\
\hline Gamma & $0.999 * * *$ & 4374.623 & $0.123 * * *$ & 5.203 & $0.973 * * *$ & 50.087 & $0.970 * * *$ & 57.338 \\
\hline $\begin{array}{l}\text { Likelihood function } \\
\text { value }\end{array}$ & -156.477 & & -163.970 & & -142.672 & & -129.925 & \\
\hline LR inspection & $97.539 * * *$ & & $82.553 * * *$ & & $125.148^{* * *}$ & & $150.643^{* * *}$ & \\
\hline
\end{tabular}

Note. When ineffective of parameter estimated value is negative, it has positive influence on the efficiency.

From the model 2 to 5 of calculation results, it is not hard to see that the value $\gamma$ is greater than 0.8 and passed inspection under the significance level of less than $1 \%$. While parameters $\beta 0, \beta 1$ and $\beta 2$ of model 2 to 5 all passed the significance level test and in the same direction, all is positive. In R\&D input of capital and human resources, the increase of the two basic resources have promote effect on regional scientific and technological innovation of new products and final products in our country at present, have a positive influence.

After joined the technical efficiency factors, without considering interaction of model 2 and joined the capital item LnK interaction of model 3, it has two variable parameters of technical efficiency have not reached significant level, so we do not discuss. But joined the human interaction $\mathrm{LnL}$ of model 4 and joined the capital and manpower double interaction of model 5, the parameter estimation results of efficiency are all passed the significant test results and in the same direction, the statistical properties have improved significantly. Among them, the parameter $\delta 1$ and $\delta 3$ are positive, it showed that the stock of patent has more negative impact on scientific and technological innovation than technology purchase in enterprise, this may indicate the current technology transfer section existed defects in our system of industry-university-research cooperation , many enterprises only focus on technology in the market purchase and the introduction of domestic and foreign patent, but can't get effective digestion of the introduction. On the one hand may be traditional developed countries try to maintain their own core competitiveness and continue to absorb the economic considerations, so they often output relatively unadvanced technology patent to developing countries and carry out blockade on cutting-edge technology; On the other hand may be due to the bad exchanges and communication between patent holder of 
patent inventor of upstream and downstream, which results in the patent purchase has a good digestive application into economic output, leading to the waste of resources. Parameter $\delta 2$ and $\delta 4$ are negative, the two parameters shows that industry-university-research cooperation level and the transformation of the enterprise ability have a positive influence on scientific and technological innovation, at present our country all levels of government are increasingly pay attention to the level and quality of "industry-university-institute" cooperation, innovation process of the enterprise as the center and good upstream and research institutions can raise the level of the regional innovation synergy, effectively improve the coordination level of regional innovation, improve the level of science and technology innovation of economic transformation. The enterprise itself funding input of digestional application and technical transformation has direct influence on the output of new products, so the parameter is also very big, shows that the results are postive as significant as expected.

(3) based on the model 5, and further calculated about 30 provinces in 2005-2011, seven years of scientific and technological innovation efficiency, by stochastic frontier analysis method, as shown in Table 4.

Table 4. Estimating technological innovation efficiency of 30 provinces in China based on the model 5 of SFA method

\begin{tabular}{|c|c|c|c|c|c|c|c|c|}
\hline $\begin{array}{l}\text { provinces } \\
\text { regions }\end{array}$ & and & 2005 & 2006 & 2007 & 2008 & 2009 & 2010 & 2011 \\
\hline Beijing & & 0.222 & 0.296 & 0.499 & 0.516 & 0.296 & 0.349 & 0.358 \\
\hline Tianjin & & 0.757 & 0.749 & 0.720 & 0.836 & 0.726 & 0.771 & 0.721 \\
\hline Hebei & & 0.179 & 0.213 & 0.260 & 0.358 & 0.323 & 0.341 & 0.437 \\
\hline Shanxi & & 0.163 & 0.173 & 0.193 & 0.257 & 0.256 & 0.238 & 0.270 \\
\hline Neimenggu & & 0.195 & 0.165 & 0.142 & 0.189 & 0.266 & 0.263 & 0.201 \\
\hline Liaoning & & 0.249 & 0.309 & 0.332 & 0.464 & 0.507 & 0.419 & 0.490 \\
\hline Jilin & & 0.526 & 0.593 & 0.630 & 0.846 & 0.949 & 0.613 & 0.879 \\
\hline Heilongjiang & & 0.151 & 0.126 & 0.158 & 0.173 & 0.168 & 0.181 & 0.162 \\
\hline Shanghai & & 0.836 & 0.856 & 0.855 & 0.923 & 0.780 & 0.861 & 0.916 \\
\hline Jiangsu & & 0.656 & 0.508 & 0.669 & 0.865 & 0.773 & 0.893 & 0.882 \\
\hline Zhejiang & & 0.873 & 0.636 & 0.763 & 0.878 & 0.673 & 0.820 & 0.870 \\
\hline Anhui & & 0.228 & 0.204 & 0.268 & 0.337 & 0.399 & 0.510 & 0.627 \\
\hline Fujian & & 0.565 & 0.457 & 0.503 & 0.527 & 0.417 & 0.503 & 0.562 \\
\hline Jiangxi & & 0.148 & 0.204 & 0.217 & 0.277 & 0.194 & 0.277 & 0.293 \\
\hline Shandong & & 0.621 & 0.555 & 0.653 & 0.821 & 0.878 & 0.935 & 0.950 \\
\hline Henan & & 0.225 & 0.243 & 0.284 & 0.373 & 0.313 & 0.337 & 0.421 \\
\hline Hubei & & 0.256 & 0.191 & 0.325 & 0.479 & 0.367 & 0.493 & 0.531 \\
\hline Hunan & & 0.258 & 0.243 & 0.303 & 0.410 & 0.484 & 0.591 & 0.631 \\
\hline Guangdong & & 0.912 & 0.688 & 0.725 & 0.930 & 0.890 & 0.962 & 0.970 \\
\hline Guangxi & & 0.265 & 0.250 & 0.324 & 0.356 & 0.378 & 0.434 & 0.446 \\
\hline Hainan & & 0.590 & 0.448 & 0.319 & 0.173 & 0.018 & 0.163 & 0.070 \\
\hline Chongqing & & 0.338 & 0.366 & 0.473 & 0.681 & 0.674 & 0.890 & 0.878 \\
\hline Sichuang & & 0.203 & 0.249 & 0.298 & 0.431 & 0.470 & 0.366 & 0.374 \\
\hline Guizhou & & 0.094 & 0.128 & 0.139 & 0.155 & 0.137 & 0.222 & 0.535 \\
\hline Yunnan & & 0.050 & 0.126 & 0.187 & 0.191 & 0.160 & 0.152 & 0.164 \\
\hline Shanxi & & 0.094 & 0.118 & 0.129 & 0.149 & 0.167 & 0.226 & 0.240 \\
\hline Gansu & & 0.072 & 0.119 & 0.162 & 0.175 & 0.107 & 0.219 & 0.274 \\
\hline Qinghai & & 0.019 & 0.089 & 0.068 & 0.121 & 0.084 & 0.023 & 0.011 \\
\hline Ningxia & & 0.072 & 0.073 & 0.061 & 0.112 & 0.122 & 0.116 & 0.141 \\
\hline Xinjiang & & 0.044 & 0.045 & 0.092 & 0.173 & 0.142 & 0.199 & 0.171 \\
\hline Average & & 0.329 & 0.314 & 0.358 & 0.439 & 0.404 & 0.446 & 0.483 \\
\hline
\end{tabular}

By drawing the following line chart, it is not hard to see that both in the whole range and eastern, central and western areas from 2005 to 2011, scientific and technological innovation efficiency is in a concussion slow growth trend at present. Regional technological innovation efficiency since 2008, after reaching a peak, down to a trough in 2009 , which is related with the impact of the financial crisis continued fermentation, the global economic recession led to our product exports shrink substantially, and caused a tremendous negative impact on 
production for the domestic new product. But from another level it also has contributed to the various types of enterprises' scale in China to accelerate the pace of independent innovation, and enhance the competitiveness of advantage, cooperate with the elevant policies and regulations in the past two years with a national level that issued a series of "establish the innovation main body status of enterprises", and combined with the active prosperity of technology market and the perfection of mature production-study-research cooperation network, the regional technological innovation efficiency in China had a significant rebound in ascension in 2010, and hit a new high in 2011, which explains the development trend is good.

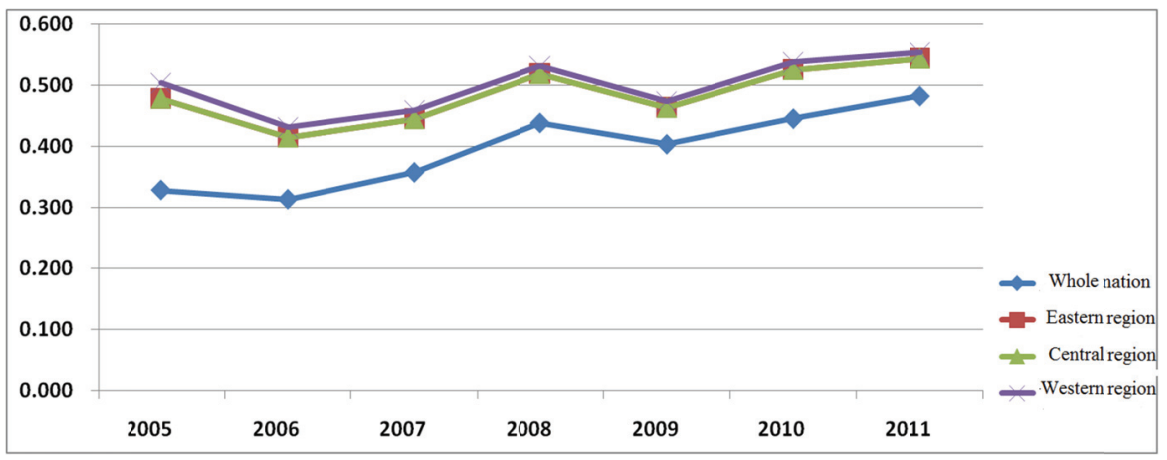

Figure 1. Line diagram of regional technological innovation efficiency from 2005 to 2011 in China

\section{Conclusion}

Through this paper using the stochastic frontier analysis research on regional technological innovation efficiency and influencing factors in China with viewing enterprise as the main body, we get the following conclusion:

(1) From the calculated parameters, the $R \& D$ expenditure has bigger promotion on the output of the regional innovation in science and technology than R\&D full-time staff equivalent, the capital investment impact on scientific and technological innovation efficiency is still stronger than the human input, description of independent technology innovation in our country at present is still largely on capital intensive development, and our country's science and technology activity staffing use, incentive mechanism and so on, may still need to be further optimized structure.

(2) In several major factors that may affect the efficiency of regional scientific and technological innovation withing the enterprise as the leading factors, the cooperation level of industry-university-research and their own absorption and transformation of technological ability has a positive effect on innovation efficiency, and its own stock of patents and technology import and purchase have a negative impact on innovation efficiency. It is easy to see, abandoning the pure downstream enterprises to upstream research institutions on technology purchase and in a lack of a traditional way to deeper cooperation and communication, then turn to the actors of industry-university-research break through the link boundaries, establish flat and internalization of industry-university-research cooperation innovation network alliance, and realize synergistically interface innovation, which are worthy for enhancing the regional innovation efficiency in China.

(3) From the longitudinal time series, affected by the depth of fermentation during the global financial crisis continues in 2005-2011, new product production in large and medium-sized enterprises for the output of regional technological innovation efficiency in China is in a shock rise trend, the overall efficiency values fluctuate between $0.3 \sim 0.5$, which is apart from the ideal state and remained a big gap, there is still a considerable room to improve in the future.

\section{Acknowledgement}

This paper is sponsored by National Natural Science Foundation of China (Grant No. 71073151).

\section{References}

Aigner, D. J., \& Lovell, C. A. (1977). Formulation and estimation of stochastic frontier production functions models. Journal of Econometrics, (1), 21-37. http://dx.doi.org/10.1016/0304-4076(77)90052-5

Bai, J. H. (2010). The empirical study of regional innovation efficiency in China. Nanjing: Nanjing Aerospace university. 
Feng, Z. J. (2006). Enterprise is the main body of independent innovation. Journal of Management Science, and Science and Technology, (4), 5-6.

Gu, X. S., Chi, G. T., \& He, C. (2010). Based on clustering and factor analysis of building the evaluation index system of science and technology. Science, (4), 508-514.

He, F., Rong, C., \& He, L. C. (2004). SFA model and its application in our country technical efficiency measurement. Journal of Systems Engineering Theory and Practice, (5), 46-50.

Wang, J., Sun, Y. T., \& Liu, F. C. (2012). Enterprise technology innovation main body status of the study in China. China Soft Science, (9), 146-153.

\section{Copyrights}

Copyright for this article is retained by the author(s), with first publication rights granted to the journal.

This is an open-access article distributed under the terms and conditions of the Creative Commons Attribution license (http://creativecommons.org/licenses/by/3.0/). 